\title{
The hot hand of history
}

\author{
We may not have known we were doing it, but humans have been \\ changing the climate for thousands of years, a new theory suggests. Could \\ our ancestors have saved us from an ice age? Betsy Mason investigates.
}

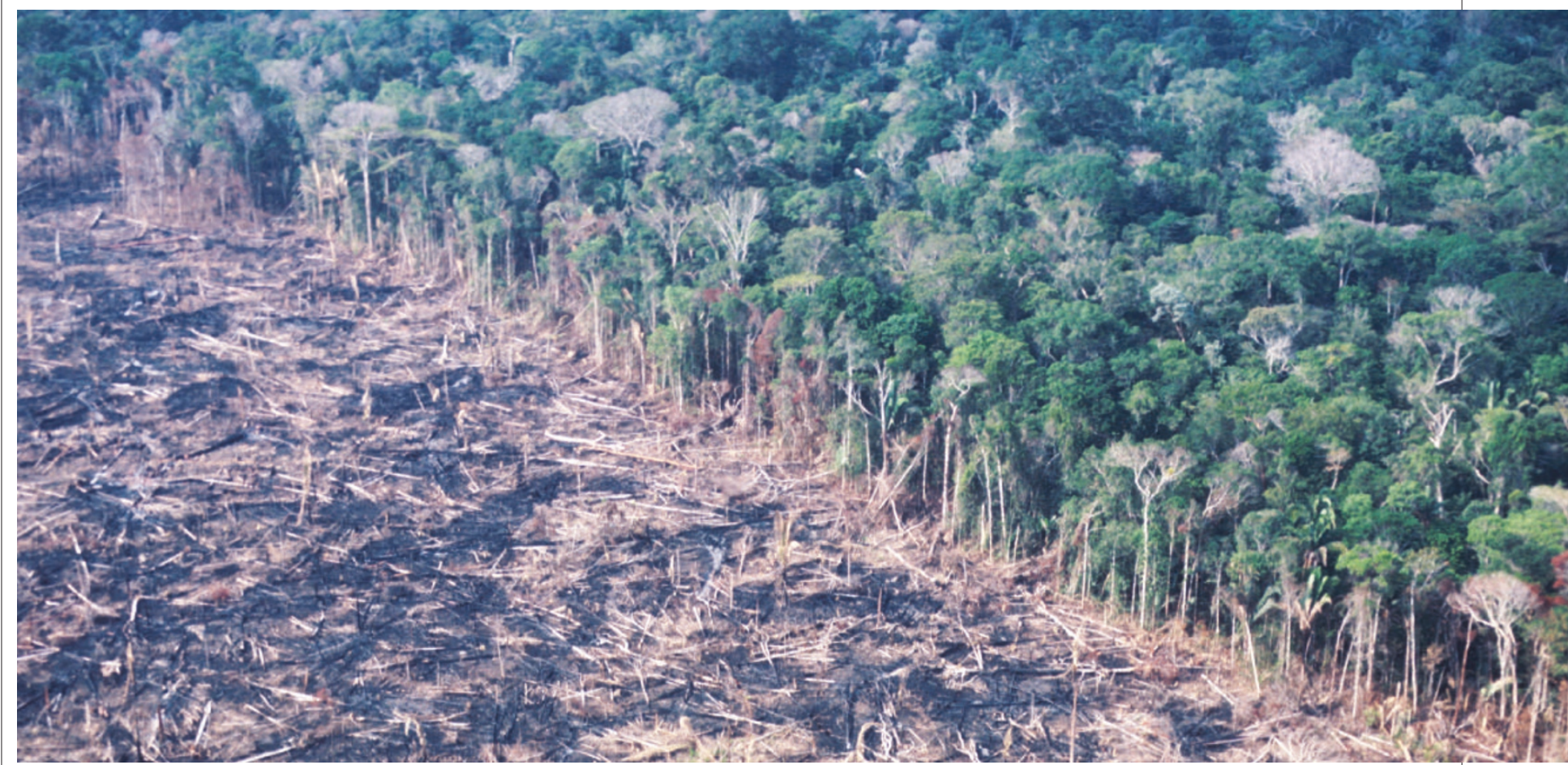

Clear cut: did deforestation 8,000 years ago set in motion a pattern of global warming that has since staved off a mini ice age?

ess than four centuries ago, life was colder in the northern latitudes than it is today. Alpine glaciers advanced, frost killed ancient orange groves in China, and Londoners held winter festivals on the frozen Thames. The Little Ice Age began around 1300 and lasted some 600 years. But according to a new theory, similar or even worse conditions might prevail today had it not been for the activities of prehistoric people.

Most scientists agree that humans have had a hand in warming Earth's climate since the industrial revolution - some even argue that we are living in a new geological epoch, dubbed the Anthropocene. But a respected climate scientist is now claiming that our involvement in climate change began thousands of years earlier and has led to more than twice as much warming as previously estimated - enough to stave off a mini ice age.

According to Bill Ruddiman, an emeritus professor at the University of Virginia, Charlottesville, humans first began to affect the climate when clear-cutting of forests for agriculture spread from the eastern Mediterranean to Eurasia 8,000 years ago. The process boosted atmospheric levels of carbon dioxide - the main greenhouse gas - by releasing carbon stored in the trees. Then, about 5,000 years ago, southeast Asians inadvertently began adding the greenhouse gas methane to the atmosphere when they flooded fields to grow rice, effectively creating artificial wetlands.

As a result, Ruddiman estimates that by 1800 , pre-industrial deforestation and farming had increased Earth's surface temperature by an average of $0.8^{\circ} \mathrm{C}$ - nearly twice the rise attributed to human activity since 1850 . The difference was even greater at higher latitudes - about $2{ }^{\circ} \mathrm{C}$ - enough to stop glaciers from forming in northern Canada and to render London and New York more temperate.

\section{Warm reception}

Since Ruddiman described his theory in December at the American Geophysical Union's annual meeting in San Francisco and in the journal Climatic Change, some climate scientists have been warming to the idea. "I have been thinking more and more that he may be on to something," says geologist Thomas Crowley of Duke University in Durham, North Carolina.

Many of those who spoke to Nature said that they might have dismissed the idea out of hand had it come from another source. But Ruddiman has a reputation for careful work. "He doesn't lay an idea out before he's really, really ready," says former graduate student Maureen Raymo, now a palaeoclimatologist at Boston University. And he has bucked conventional wisdom before. In 1989, he was the first to propose that the rise of the Himalayas 40 million years ago altered the climate of Asia $^{2}$, an idea considered outlandish at the time but now generally regarded as correct.

But for other climate scientists, sizeable doubts remain. They stress that, so far, the idea is based only on correlations, and that Ruddiman has yet to present hard data. The prehistoric rise in greenhouse gases could easily be the result of other factors, they say, such as subtle changes in Earth's orbit or the release of carbon by the oceans.

Ruddiman first began to suspect an early human influence on the atmosphere several years ago, when studying sample cores extracted from ice in a region of the Antarctic interior called Vostok ${ }^{3}$. The 3,500-metrethick sheet formed over 400,000 years as snow accumulated and compacted into ice, preserving a continuous record of Earth's atmosphere in pockets of air.

In his analysis of air bubbles in the Vostok ice, Ruddiman found that atmospheric levels of methane waxed and waned every 23,000 years for the length of the ice-core record. The methane cycle seems to be linked to the 'wobble' of Earth's axis, which periodically causes warmer summers. This in turn 
great deal of carbon as solid calcium carbonate. Looking at deep-sea sediment cores, Broecker's team detected a drop in carbonate concentrations that corresponded to the rise in atmospheric $\mathrm{CO}_{2}$. That suggested the carbon came from the ocean, not burned forests.

Ruddiman argues that Broecker's theory and other hypotheses ${ }^{5}$ fail to explain why the current interglacial period - the time between ice ages - is so different from the previous three, each of which saw a drop in both methane and carbon dioxide as the next ice age approached. The sudden upswing in greenhouse gases is completely unprecedented, Ruddiman argues.

But it may not be unique, says Michel Crucifix of the Hadley Centre for Climate Prediction and Research in Exeter, UK. He has studied the partial record in the Vostokice core from the next oldest interglacial period and says that it also seems to be different. So it's too early to rule out natural explanations such as changes in Earth's orbit, he says.

Ice cores from Vostok in Antarctica reveal anomalies in Earth's atmosphere 5,000-8,000 years ago.

strengthens the monsoons that drench the tropics, expanding the surface area of wetlands - which disgorge methane from decaying plant matter.

But Ruddiman was intrigued by an anomaly in the record. "At 11,000 years ago there's a methane peak that's exactly where it should be," he says. "Then the methane starts going down just the way it's supposed to. But all of a sudden, 5,000 years ago, it just turns around and heads right back up." At the same time, the main known source of methane, the tropical wetlands, continued to dry out. "There's no natural explanation that's going to work if it's breaking the natural rules, so the only thing I could conceive of is humans," Ruddiman says.

\section{Grains of truth?}

Ruddiman found hints that human activity might have caused the reversal in the archaeology literature. As it turns out, 5,000 years ago is when the people of southeast Asia first began transplanting rice seedlings to flooded fields to protect them from weeds and dry spells. Ruddiman proposed that the rice paddies took over producing methane where the tropical bogs had left off ${ }^{3}$.

But methane is only part of the story. The $\mathrm{CO}_{2}$ record in the Vostokice cores, although more complex, also seems to break a trend in recent millennia. In addition to the 23,000year cycle, levels of $\mathrm{CO}_{2}$ in the atmosphere fluctuate on 100,000-year and 41,000-year cycles. Although the causes of this are not yet fully under-

stood, all three cycles put atmospheric $\mathrm{CO}_{2}$ on the downswing for the past 11,000 years. Yet 8,000 years ago, $\mathrm{CO}_{2}$ levels began to rise.

Here again, Ruddiman cites a corresponding trend in the archaeological record. Around that time, certain domesticated grains first appear in soil sediments from southern Europe, marking the spread of farming from the Near East. Lower pollen counts from sediments in China suggest widespread deforestation as farmers cleared more land. The advent of more efficient ploughs 6,000 years ago further accelerated the trend. "Most of Eurasia was deforested by the time of Christ," says Ruddiman.

Even in historic times, there are intriguing correlations between unexplained drops in atmospheric carbon and human activity, Ruddiman points out. For instance, drops in $\mathrm{CO}_{2}$ levels in the third to sixth centuries and again in the fourteenth century correspond to

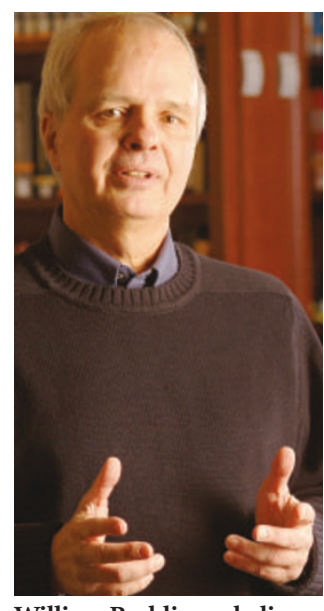

William Ruddiman believes that our ancient ancestors changed Earth's climate. episodes of bubonic plague that killed $25-45 \%$ of the population of Europe and western Asia. Many acres of abandoned farmland would have reverted to forest, pulling $\mathrm{CO}_{2}$ back out of the atmosphere, according to Ruddiman. And a third $\mathrm{CO}_{2}$ drop between 1500 and 1750 coincides with the death of about 90\% of indigenous Americans from newly imported diseases.

Ruddiman is not the first to tackle the ice-core anomalies. In 1999, one of the world's leading climate scientists, Wallace Broecker of Columbia University in New York, proposed that much of the $\mathrm{CO}_{2}$ came from the oceans ${ }^{4}$. The deep sea stores a

\section{Root cause}

Fortunat Joos of the University of Bern in Switzerland is also unconvinced. He says that Ruddiman has underestimated the role of the oceans in absorbing carbon released through deforestation. Joos calculates that humans would have had to clear more than twice as much land as Ruddiman estimates to cause a $0.8^{\circ} \mathrm{C}$ rise in temperature. He also points out that loading the atmosphere with carbon from vegetation would cause a drop in the ratio of two common carbon isotopes, carbon-13 and carbon-12. The drop seen in the ice-core data is less than half what it should be if Ruddiman is right, Joos says.

Ruddiman says that an important test of his theory will be to work out more quantitatively whether deforestation was extensive enough to cause the rise in $\mathrm{CO}_{2}$ levels. Pollen counts from ancient lake sediments, which provide an estimate of local tree density, may offer clues. And a new Antarctic ice core that extends back about 900,000 years, recently obtained by a Swiss team, may reveal whether the current warm period is truly unique.

As grateful as we might be to our ancestors for saving us from a mini ice age — if, in fact, they did - climate scientists warn that we shouldn't conclude that modern global warming is a good thing. We are now boosting the amount of $\mathrm{CO}_{2}$ in the atmosphere ten times faster our ancestors did, and to levels outside the range of natural fluctuation. We may not miss winter fairs on the Thames, but no one really wants flooded coastal cities.

\section{Betsy Mason recently completed an internship in}

\section{Nature's Washington DC office.}

1. Ruddiman, W. F. Clim. Change 61, 261-293 (2003).

2. Ruddiman, W. F. \& Kutzbach, J. E. J. Geophys. Res. 94,

18409-18427 (1989).

. Ruddiman, W. F. \& Thomson, J. S. Quat. Sci. Rev. 20, 1769-1777 (2001)

4. Broecker, W. S. et al. Paleoceanography 14, 744-752 (1999) . Indermühle, A. et al. Nature 398, 121-126 (1999). 